\title{
Association between transitional care factors and hospital readmission after transcatheter aortic valve replacement: a retrospective observational cohort study
}

Andrew Czarnecki $1^{1,24^{*}}$ (D) Peter C. Austin ${ }^{3,4}$, Stephen E. Fremes ${ }^{1,3}$, Jack V. Tu ${ }^{1,2,3,4}$, Harindra C. Wijeysundera ${ }^{1,2,3,4}$ and Dennis T. Ko $\mathrm{K}^{1,2,3,4}$

\begin{abstract}
Background: Studies have shown that patients who undergo trans-catheter aortic valve replacement (TAVR) have high rates of hospital readmission. Our objectives were to identify the causes of readmission after TAVR, determine whether transitional care factors were associated with a reduction in readmission and to identify other predictors that could be used to target quality improvement efforts.

Methods: We conducted a chart abstraction study that included all patients who underwent TAVR in Ontario, Canada between 2007 and 2013 and survived to hospital discharge. These data were linked to provincial administrative databases. The association between transitional care factors (home care, rehabilitation, family physician and cardiologist follow-up) and 1-year hospital readmission was examined using a time-to-event analysis. Cause-specific hazards models were used to account for the competing risk of death.

Results: There were 937 patients in the cohort and the rate of readmission at 1-year was 49\%. The most common causes of readmission were heart failure and bleeding. Rehabilitation ( $\mathrm{HR} \mathrm{1.34,95 \%} \mathrm{Cl} \mathrm{1.11-1.62;} p=0.002$ ) and cardiologist follow-up (HR 1.41,95\% Cl 1.14-1.75; $p=0.002$ ) were both associated with higher readmission rates. While, home care (HR 1.18, 95\% Cl 0.96-1.44; $p=0.12$ ) and family physician follow-up (HR 1.04, 95\% Cl 0.85-1.28; $p=0.71)$ were not associated with readmission.
\end{abstract}

Conclusion: Readmission post TAVR is common; however, we did not identify any transitional care factors associated with reductions in hospital readmission. This suggests ongoing research is required to identify targets for improvement in post-procedural care.

Keywords: Transcatheter aortic valve replacement, Aortic stenosis, Hospital readmission, Transition of care

\section{Background}

Transcatheter aortic valve replacement (TAVR) has revolutionized the treatment of elderly and high-risk patients with aortic stenosis (AS), as the number of patients with AS continue to rise [1]. However, recent studies have shown that hospital readmission after TAVR is very common with rates at 30-days ranging from 15

\footnotetext{
* Correspondence: andrew.czarnecki@sunnybrook.ca

${ }^{1}$ Schulich Heart Centre, Division of Cardiology, Sunnybrook Health Sciences

Centre, 2075 Bayview Ave, Toronto, Ontario M4N 3M5, Canada

${ }^{2}$ Department of Medicine, University of Toronto, Suite RFE 3-805, 200

Elizabeth Street, Toronto, Ontario M5G 2C4, Canada

Full list of author information is available at the end of the article
}

to $21 \%$ and 1 -year rates are as high as $53 \%[2,3]$. While the goal of TAVR is to alter disease trajectory, these data suggest that despite treatment of AS these patients continue to be high utilizers of healthcare resources.

Despite expanding indications and rising volumes, the cause of hospital readmission after TAVR is still poorly understood and modifiable factors that could be used to design targeted interventions to reduce these hospitalizations have not be identified. While transitional care factors, such as physician follow-up, have been associated with lower readmission rates in other disease states, the impact of these factors in the TAVR population is

(c) The Author(s). 2019 Open Access This article is distributed under the terms of the Creative Commons Attribution 4.0 International License (http://creativecommons.org/licenses/by/4.0/), which permits unrestricted use, distribution, and reproduction in any medium, provided you give appropriate credit to the original author(s) and the source, provide a link to the Creative Commons license, and indicate if changes were made. The Creative Commons Public Domain Dedication waiver (http://creativecommons.org/publicdomain/zero/1.0/) applies to the data made available in this article, unless otherwise stated. 
unknown [4-8]. Accordingly, our objectives were to identify the causes of hospital readmission within 1 year of TAVR, to determine whether transitional care factors are associated with a reduction in readmission, and to identify any modifiable determinants that could be used as targets for improvement.

\section{Methods}

A retrospective observational cohort study was performed using chart abstraction data linked to administrative datasets held at the Institute of Clinical Evaluative Sciences (ICES), Toronto, Ontario, Canada.

\section{Data sources}

We conducted a chart abstraction study in Ontario to capture all TAVR procedures performed from 2007 to $2013[9,10]$. The database included detailed demographic, clinical and procedural data. Data from the clinical database were linked using unique encoded identifiers to administrative databases and analyzed at ICES to protect patient confidentiality. This comprehensive chart abstraction was performed by six trained nurse abstractors using standardized data definitions.

The Canadian Institutes for Health Information Discharge Abstract Database was used to identify hospital readmissions and comorbidities. Validated disease state definitions were used to establish comorbidities including diabetes, hypertension, and heart failure [11-13]. Frailty was identified based on John Hopkins Ambulatory Clinical Groups software which uses a proprietary set of diagnostic codes found in administrative data [14]. The Ontario Health Insurance Plan and the ICES Physician Database were used to identify physician visits and their specialty, respectively. The Home Care Database and the National Rehabilitation Database facilitated identification of home care services and use of in-patient rehabilitation. Finally, the Registered Persons Database was used to assess vital status.

\section{Cohort}

All patients who underwent TAVR in Ontario between April 1st, 2007 and March 31st, 2013 were included. Patients were excluded if they died prior to discharge during the index hospitalization. All patients had a minimum follow-up of 1 year.

\section{Outcomes}

The primary outcome was all-cause readmission within 1 year of discharge from the index TAVR hospitalization.

\section{Transitional care factors}

To evaluate the association between transitional care interventions and hospital readmission after TAVR, we assessed the following factors: follow-up with a family physician, follow-up with a cardiologist, use of home care services and in-patient rehabilitation. Home care services were considered to be present if any in-home service was delivered after discharge and includes: nurse visitation, physiotherapy, occupational therapy, personal support worker visits, as well as homemaking services. Due to the inability to accurately determine whether a physician visit occurred during hospitalization or as an out-patient, visits that occurred on the same day as hospital admission were excluded.

\section{Statistical analysis}

Patient characteristics were compared based on the presence or absence of readmission within 1 year. Standard descriptive statistics were used. Causes of readmission were characterized based on aggregate diagnoses using groupings of ICD-10 codes [9].

Cause-specific proportional hazards models were used for modeling the hazard of readmission, treating death prior to readmission as a competing risk (known to be $20 \%$ at 1 year) [3]. This approach models the instantaneous hazard of an of event of interest in subjects who are currently event-free (i.e, who are alive and have not yet been readmitted to hospital). This strategy is appropriate when studying 'etiologic' associations [15]. Variables for inclusion in the regression model were chosen 'a priori', based on the clinical knowledge of content experts and prior literature [2,16-18]. The following variables were included: demographics (age, sex, living status), clinical characteristics [frailty, New York Heart Association (NYHA) functional class, left ventricular function], comorbidities (diabetes, dementia, heart failure, myocardial infarction, atrial fibrillation, lung disease, cerebrovascular disease, dialysis, peripheral vascular disease, liver disease, peptic ulcer disease, bleeding), previous cardiac interventions [percutaneous coronary intervention (PCI), coronary-aortic bypass surgery], lab values [hemoglobin, estimated glomerular filtration rate (eGFR)], prior health care utilization (hospitalization 30 days prior to TAVR), procedural factors (valve-in-valve, elective vs urgent, vascular access site, self-expandable vs balloon expandable valve), post-procedural complications (permanent pacemaker, bleeding/vascular complication/transfusion, stroke, delirium), post-TAVR echocardiographic findings (aortic regurgitation, mitral regurgitation), transitional care factors and year of the TAVR procedure. Collinearity was assessed using variance inflation factors. Time to first readmission was modelled in all analyses. Patients were censored at maximum follow-up or if death occurred before readmission. Transitional care factors were included in the regression model as time-varying covariates. Robust sandwich variance estimates were used to account for clustering of patients within hospitals. The incidence of readmission and death over time were estimated using cumulative incidence function (CIF) curves. 
Two sensitivity analyses were performed. First, due to the concern that factors such as physician follow-up were in the causal pathway for readmission and to better understand the influence of transitional care factors, we performed a landmark analysis assessing outcomes occurring between day 31 and day 365 . In this analysis, patients who were readmitted or died within the first 30 days were excluded. Transitional care factors were operationalized in a dichotomous fashion based on their occurrence within the first 30 days. Secondly, due to concern that early TAVR experience may not be representative of current practice, we selected a cohort of patients who underwent TAVR after 2010 for separate analysis. The primary analysis was repeated in this sub-cohort to ensure overall consistency in our results.

All analyses were performed using SAS statistical software, version 9.3 (SAS Institute, Cary, NC). A 2 -tailed $p$ value of $<0.05$ was considered significant.

\section{Results}

\section{Baseline characteristics}

There were 999 patients who underwent TAVR between 2007 and 2013. After excluding 62 patients (6.2\%) who did not survive to hospital discharge, our final study cohort included 937 patients (see Fig. 1). At least 1 year follow-up was available for all patients and mean follow-up was $2.6+/-1.4$ years (standard deviation). There were 462 patients readmitted within 1-year of the index hospitalization, representing $49.3 \%$ of the cohort. Among those readmitted, median time to readmission was 64 days (IQR 17-157). Patients readmitted had higher baseline NYHA class and a trend towards more frailty (Table 1). There were large baseline differences in preexisting cardiac conditions, including atrial fibrillation $(37.9 \%$ vs $26.1 \%, p<0.001)$, heart failure $(50.2 \%$ vs $37.7 \%, \mathrm{p}<0.001)$ and prior $\mathrm{PCI}$ (35.9\% vs $28.4 \%, p=0.01)$, all higher in readmitted patients. Patients who were readmitted had higher rates of lung disease $(22.7 \%$ vs $12.6 \%, p<0.001)$ and bleeding history $(29.9 \%$ vs $18.9 \%, \mathrm{p}<0.001)$.

In terms of transitional care factors, in-patient rehabilitation $(17.1 \%$ vs $8.6 \% ; \mathrm{p}<0.001)$ and home care utilization $(44.2 \%$ vs $35.2 \% ; p=0.005)$ within the first 30 days were both more frequent in patients readmitted. There was no difference in family physician follow-up, but cardiologist follow-up was more common in patients readmitted $(65.6 \%$ vs $54.3 \% ; p<0.001)$. Family physician follow-up occurred at a median of 7 days post discharge (IQR 3-17 days) while cardiologist follow-up occurred at median of 26 days (IQR 11-41 days).

\section{Procedural characteristics, complications and outcomes}

There was no difference in procedural urgency between patients with and without hospital readmission (Table 2). Non-trans-femoral vascular access was more common in patients readmitted $(27.9 \%$ vs $22.9 \%, p=0.05)$. Procedural complications including delirium (11.7\% vs $5.5 \%)$ and bleeding/transfusion/vascular complications (38.1\% vs $25.7 \%$ ) were significantly more prevalent in readmitted patients.

\section{Mortality and causes of readmission}

At 1 year, 126 patients (13.4\%) had died since discharge from the index hospitalization (Fig. 2). The majority of patients who died in the year after TAVR did so during a readmission event. The rate of 30-day readmission was $16.8 \%$ (157 patients) and the 1-year readmission rate was 49.3\% (462 patients). The causes of readmission are shown in Fig. 3. The top readmission diagnoses at 1 year were heart failure and bleeding.

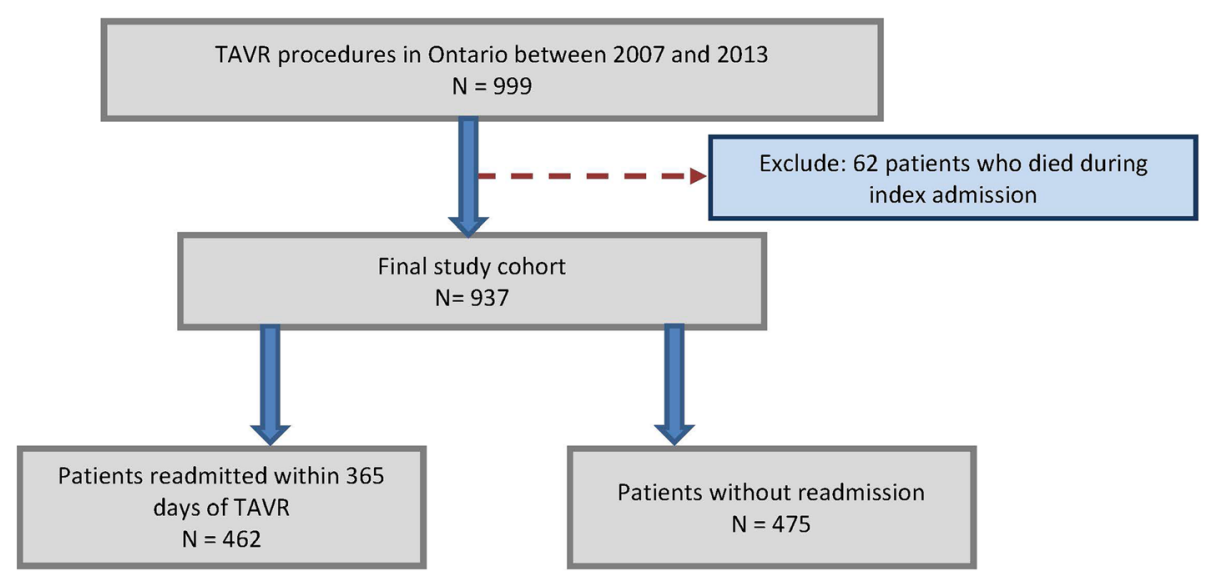

Fig. 1 Study cohort creation 
Table 1 Baseline characteristics of patients readmitted within 1 year

\begin{tabular}{|c|c|c|c|c|}
\hline \multirow[t]{2}{*}{ Characteristic } & Readmitted & Not Readmitted & Overall & \multirow[t]{2}{*}{$p$ value } \\
\hline & $N=462$ & $N=475$ & $N=937$ & \\
\hline \multicolumn{5}{|l|}{ Demographics } \\
\hline Age, median (IQR) & $84(79-87)$ & $83(78-87)$ & $83(78-87)$ & 0.14 \\
\hline Female & $204(44.2 \%)$ & $211(44.4 \%)$ & 415 (44.3\%) & 0.94 \\
\hline \multicolumn{5}{|l|}{ Baseline living status } \\
\hline Independent & $366(79.2 \%)$ & $400(84.2 \%)$ & $766(81.8 \%)$ & \multirow[t]{2}{*}{0.10} \\
\hline Dependent & 87 (18.8\%) & $65(13.7 \%)$ & $152(16.2 \%)$ & \\
\hline \multicolumn{5}{|l|}{ Cardiac Risk Factors } \\
\hline Diabetes & $230(49.8 \%)$ & $224(47.2 \%)$ & $454(48.5 \%)$ & 0.42 \\
\hline Dyslipidemia & $330(71.4 \%)$ & $326(68.6 \%)$ & $656(70.0 \%)$ & 0.35 \\
\hline Hypertension & $448(97.0 \%)$ & 448 (94.3\%) & $896(95.6 \%)$ & 0.05 \\
\hline \multicolumn{5}{|l|}{ Clinical Characteristics } \\
\hline \multicolumn{5}{|l|}{ NYHA Class } \\
\hline | or || & $64(13.9 \%)$ & $82(17.3 \%)$ & $146(15.6 \%)$ & \multirow[t]{3}{*}{0.01} \\
\hline III & $290(62.8 \%)$ & $308(64.8 \%)$ & $598(63.8 \%)$ & \\
\hline IV & $83(18.0 \%)$ & $52(10.9 \%)$ & 135 (14.4\%) & \\
\hline Frailty & $70(15.2 \%)$ & $54(11.4 \%)$ & $124(13.2 \%)$ & 0.09 \\
\hline Weight (kg), median (IQR) & $72(62-82)$ & $73(62-84)$ & $72(62-83)$ & 0.30 \\
\hline \multicolumn{5}{|l|}{ Cardiac comorbidities and interventions } \\
\hline Atrial fibrillation & $175(37.9 \%)$ & $124(26.1 \%)$ & 299 (31.9\%) & $<0.001$ \\
\hline Prior heart failure & $232(50.2 \%)$ & $179(37.7 \%)$ & $411(43.9 \%)$ & $<0.001$ \\
\hline Prior myocardial infarction & $115(24.9 \%)$ & $94(19.8 \%)$ & $209(22.3 \%)$ & 0.06 \\
\hline Prior $\mathrm{PCl}$ & $166(35.9 \%)$ & $135(28.4 \%)$ & $301(32.1 \%)$ & 0.01 \\
\hline Prior $C A B G$ & $133(28.8 \%)$ & $172(36.2 \%)$ & $305(32.6 \%)$ & 0.02 \\
\hline Prior AVR & $35(7.6 \%)$ & $40(8.4 \%)$ & $75(8.0 \%)$ & 0.63 \\
\hline \multicolumn{5}{|l|}{ Medical comorbidities } \\
\hline Cerebrovascular disease & $38(8.2 \%)$ & $38(8.0 \%)$ & $76(8.1 \%)$ & 0.90 \\
\hline Peripheral vascular disease & $92(19.9 \%)$ & $74(15.6 \%)$ & $166(17.7 \%)$ & 0.08 \\
\hline Dementia & $12(2.6 \%)$ & $8(1.7 \%)$ & $20(2.1 \%)$ & 0.33 \\
\hline Dialysis & $26(5.6 \%)$ & $6(1.3 \%)$ & $32(3.4 \%)$ & $<0.001$ \\
\hline Lung disease & $105(22.7 \%)$ & $60(12.6 \%)$ & $165(17.6 \%)$ & $<0.001$ \\
\hline Cancer & $67(14.5 \%)$ & $50(10.5 \%)$ & $117(12.5 \%)$ & 0.07 \\
\hline Liver disease & $10(2.2 \%)$ & $6(1.3 \%)$ & $16(1.7 \%)$ & 0.29 \\
\hline Peptic ulcer disease & $34(7.4 \%)$ & $12(2.5 \%)$ & $46(4.9 \%)$ & $<0.001$ \\
\hline Prior bleeding history & $138(29.9 \%)$ & $90(18.9 \%)$ & $228(24.3 \%)$ & $<0.001$ \\
\hline \multicolumn{5}{|l|}{ Laboratory markers } \\
\hline eGFR, median (IQR) & $54(39-70)$ & $62(46-78)$ & $58(42-74)$ & $<0.001$ \\
\hline Hemoglobin (g/L), median (IQR) & $117(105-129)$ & $124(113-134)$ & $120(109-132)$ & $<0.001$ \\
\hline \multicolumn{5}{|l|}{ Echocardiographic findings } \\
\hline Aortic valve area $(\mathrm{cm} 2)$, mean $\pm S D$ & $0.68 \pm 0.22$ & $0.70 \pm 0.24$ & $0.69 \pm 0.23$ & 0.16 \\
\hline Mean AoV $(\mathrm{mmHg})$, mean \pm SD & $46 \pm 15$ & $46 \pm 16$ & $46 \pm 16$ & 0.80 \\
\hline Left ventricular dysfunction & $120(26.0 \%)$ & $135(28.4 \%)$ & 255 (27.2\%) & 0.42 \\
\hline \multicolumn{5}{|l|}{ Composite measures } \\
\hline EuroScore II (\%), mean \pm SD & $0.07 \pm 0.07$ & $0.07 \pm 0.05$ & $0.07 \pm 0.06$ & 0.06 \\
\hline
\end{tabular}


Table 1 Baseline characteristics of patients readmitted within 1 year (Continued)

\begin{tabular}{|c|c|c|c|c|}
\hline \multirow[t]{2}{*}{ Characteristic } & Readmitted & Not Readmitted & Overall & \multirow[t]{2}{*}{$p$ value } \\
\hline & $N=462$ & $N=475$ & $N=937$ & \\
\hline Charlson Score, mean \pm SD & $2.72 \pm 2.19$ & $1.97 \pm 1.91$ & $2.34 \pm 2.09$ & $<0.001$ \\
\hline Hospitalization 30 days before TAVR & $147(31.8 \%)$ & $116(24.4 \%)$ & $263(28.1 \%)$ & 0.01 \\
\hline \multicolumn{5}{|l|}{ Transitional care factors ( $\leq 30$ days) } \\
\hline In-patient rehabilitation & 79 (17.1\%) & $41(8.6 \%)$ & $120(12.8 \%)$ & $<0.001$ \\
\hline Home care utilization & $204(44.2 \%)$ & $167(35.2 \%)$ & $371(39.6 \%)$ & 0.005 \\
\hline Family physician follow-up & $382(82.7 \%)$ & $405(85.3 \%)$ & $787(84.0 \%)$ & 0.28 \\
\hline Cardiologist follow-up & $303(65.6 \%)$ & $258(54.3 \%)$ & $561(59.9 \%)$ & $<0.001$ \\
\hline
\end{tabular}

Abbreviations: IQR interquartile range, NYHA New York Heart Association, $P C I$ percutaneous coronary intervention, CABG coronary-aorto bypass grafting, AVR aortic valve replacement, eGFR estimated glomerular filtration rate, $A o V$ aortic valve, $S D$ standard deviation

\section{Transitional care factors}

None of the transitional care factors were associated with a reduction in readmission. In-patient rehabilitation (HR 1.34, 95\% CI 1.11-1.62; $p=0.002$ ) and cardiologist follow-up (HR 1.41, 95\% CI 1.14-1.75; p = 0.002) were both associated with higher readmission rates. Home care services (HR 1.18, 95\% CI 0.96-1.44; $p=0.12$ ) and follow-up with a family physician (HR 1.04, 95\% CI $0.85-1.28 ; p=0.71$ ) were not associated with the rate of hospital readmission.

Table 2 Procedural characteristics, complications and echocardiographic findings of patients readmitted within 1 year

\begin{tabular}{|c|c|c|c|c|}
\hline \multirow[t]{2}{*}{ Characteristic } & Readmitted & Not Readmitted & Overall & \multirow[t]{2}{*}{$p$ value } \\
\hline & $N=462$ & $N=475$ & $N=937$ & \\
\hline \multicolumn{5}{|l|}{ Procedural characteristics } \\
\hline \multicolumn{5}{|l|}{ Procedure status } \\
\hline Elective & $412(89.2 \%)$ & $438(92.2 \%)$ & $850(90.7 \%)$ & \multirow[t]{2}{*}{0.11} \\
\hline Urgent & $50(10.8 \%)$ & $37(7.8 \%)$ & 87 (9.3\%) & \\
\hline \multicolumn{5}{|l|}{ Type of valve } \\
\hline Balloon-expandable & $253(54.8 \%)$ & $249(52.4 \%)$ & $502(53.6 \%)$ & \multirow[t]{2}{*}{0.02} \\
\hline Self-expandable & $193(41.8 \%)$ & $221(46.5 \%)$ & $414(44.2 \%)$ & \\
\hline Valve-in-valve & $13(2.8 \%)$ & $30(6.4 \%)$ & $43(4.62 \%)$ & 0.01 \\
\hline \multicolumn{5}{|l|}{ Vascular access site } \\
\hline Femoral artery & $325(70.3 \%)$ & $363(76.4 \%)$ & $688(73.4 \%)$ & \multirow[t]{2}{*}{0.05} \\
\hline Other & $129(27.9 \%)$ & 109 (22.9\%) & $238(25.4 \%)$ & \\
\hline \multicolumn{5}{|l|}{ Procedural complications } \\
\hline Delirium & $54(11.7 \%)$ & $26(5.5 \%)$ & $80(8.5 \%)$ & $<0.001$ \\
\hline Permanent pacemaker & $70(15.2 \%)$ & $56(11.8 \%)$ & $126(13.4 \%)$ & 0.13 \\
\hline Stroke & $10(2.2 \%)$ & $7(1.5 \%)$ & $17(1.8 \%)$ & 0.43 \\
\hline Bleeding/vascular complication/transfusion & $176(38.1 \%)$ & $122(25.7 \%)$ & $298(31.8 \%)$ & $<0.001$ \\
\hline \multicolumn{5}{|l|}{ Echocardiographic findings post-TAVR } \\
\hline \multicolumn{5}{|l|}{ Mitral regurgitation } \\
\hline Nil/trace & $133(28.8 \%)$ & $178(37.5 \%)$ & $311(33.2 \%)$ & \multirow[t]{3}{*}{0.04} \\
\hline Mild & $207(44.8 \%)$ & $195(41.1 \%)$ & $402(42.9 \%)$ & \\
\hline Moderate/Severe & $104(22.5 \%)$ & $87(18.3 \%)$ & $191(20.4 \%)$ & \\
\hline \multicolumn{5}{|l|}{ Aortic regurgitation } \\
\hline $\mathrm{Nil} /$ trace & $230(49.8 \%)$ & $277(58.3 \%)$ & $507(54.1 \%)$ & \multirow[t]{3}{*}{0.06} \\
\hline Mild & $164(35.5 \%)$ & $139(29.3 \%)$ & $303(32.3 \%)$ & \\
\hline Moderate/Severe & $53(11.5 \%)$ & 49 (10.3\%) & $102(10.9 \%)$ & \\
\hline
\end{tabular}




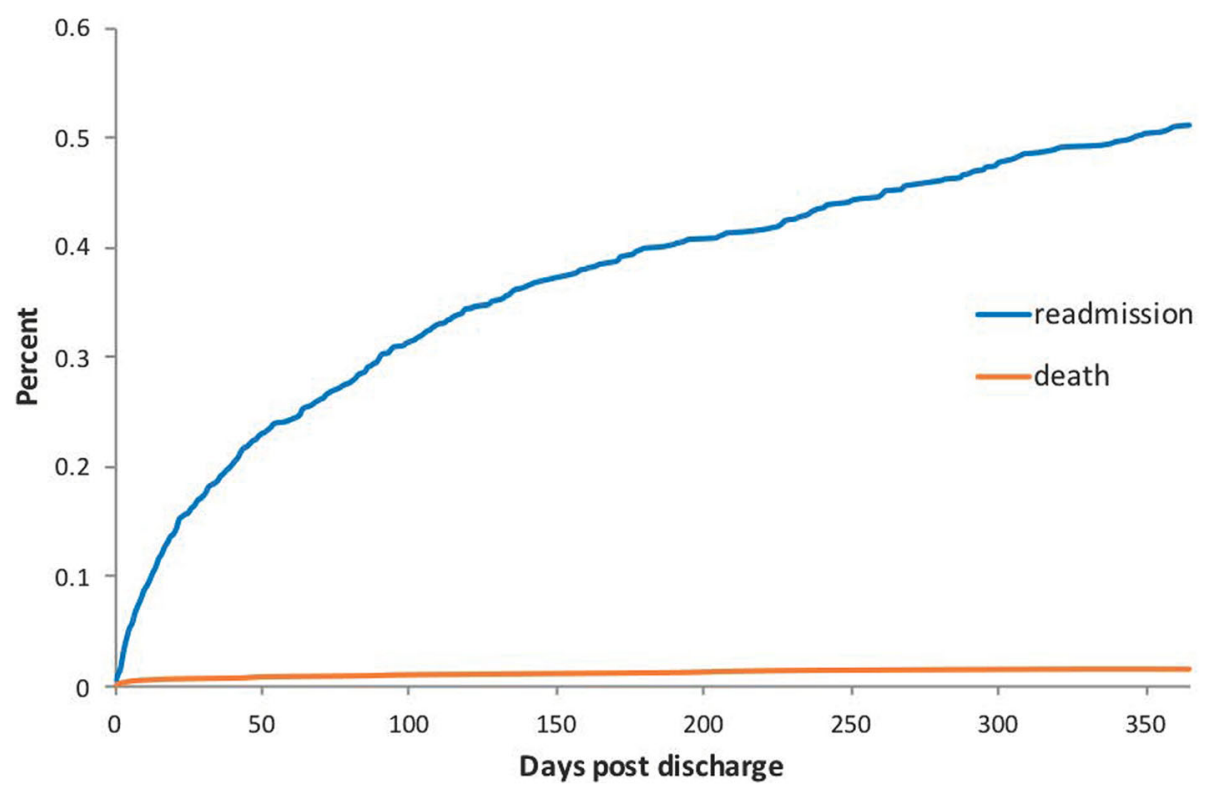

Fig. 2 Cumulative incidence curves for readmission and death without readmission. Readmission is shown in blue and death is shown in orange

\section{Predictors of readmission}

The results of the multivariable model are shown in Table 3. The only pre-existing cardiac condition associated with readmission was atrial fibrillation with a HR of 1.34 (95\% CI 1.08-1.66; $p=0.01$ ), while previous myocardial infarction, heart failure and prior PCI were not. Most medical comorbidities were not significantly associated with the rate of readmission - only peripheral vascular disease (HR 1.18, 95\% CI 1.02-1.37; $p=0.02$ ), peptic ulcer disease (HR 1.52, 95\% CI 1.09-2.12, $p=0.01$ ) and dialysis
(HR 1.67, 95\% CI 1.06-2.65; $p=0.03$ ) were associated with readmission.

Procedural characteristics and complications had inconsistent effects on readmission. Valve-in-valve procedures were strongly associated with a lower rate of readmission ( $\mathrm{HR} 0.65,95 \%$ CI $0.48-0.87, p=0.004$ ), while non-femoral vascular access was a significant predictor of higher readmission with a HR of 1.40 (95\% CI $1.08-1.81 ; \mathrm{p}=0.01$ ). The year of the TAVR procedure did not influence readmission.

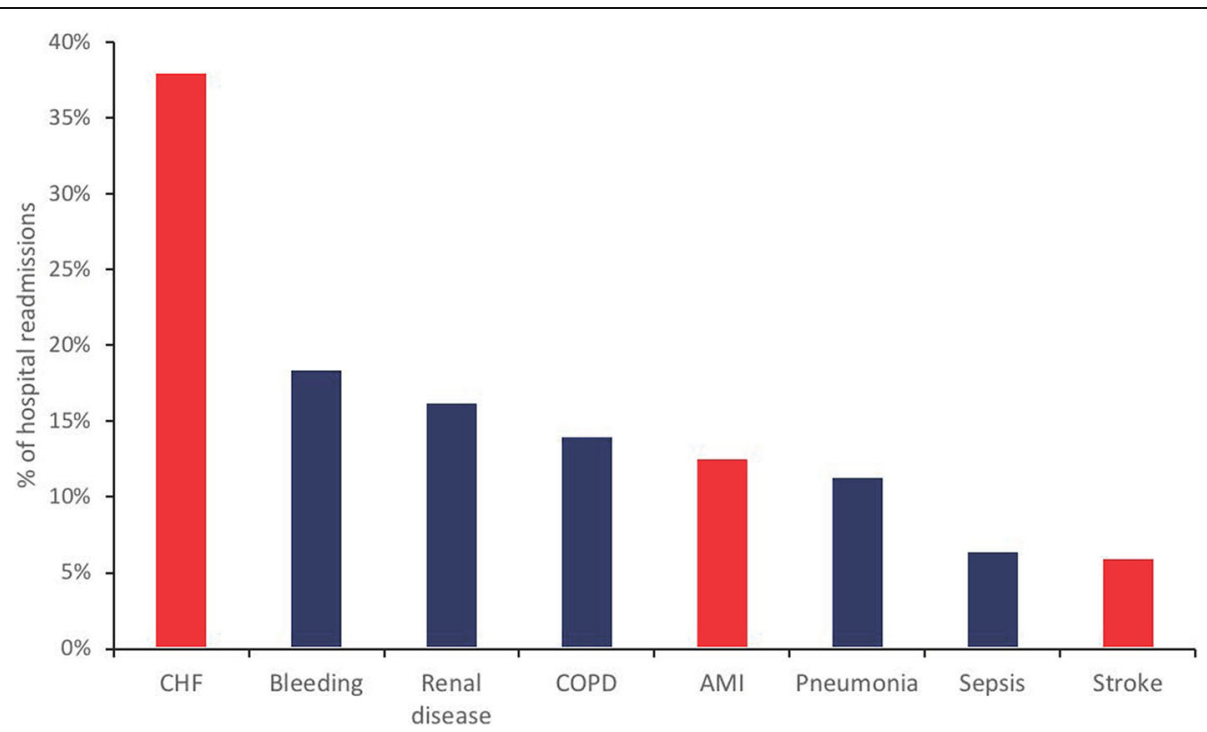

Fig. 3 Diagnoses of patients readmitted within 1-year of TAVR. Readmission diagnoses based on most-responsible diagnosis in the year following the index TAVR hospitalization (red bars represent cardiac diagnoses and blue bars represent non-cardiac diagnoses) 
Table 3 Predictors of hospital readmission within 1 year of TAVR discharge

\begin{tabular}{|c|c|c|c|}
\hline & $\mathrm{HR}$ & $95 \% \mathrm{Cl}$ & $p$ value \\
\hline \multicolumn{4}{|l|}{ Demographics } \\
\hline Age & 1.01 & $(1.0-1.02)$ & 0.20 \\
\hline Female sex & 0.72 & $(0.53-0.98)$ & 0.03 \\
\hline Dependent living & 1.03 & $(0.85-1.24)$ & 0.77 \\
\hline \multicolumn{4}{|l|}{ Clinical Characteristics } \\
\hline \multicolumn{4}{|l|}{ NYHA class } \\
\hline$|/| \mid$ & reference & & \\
\hline III & 1.00 & $(0.82-1.21)$ & 0.96 \\
\hline IV & 1.43 & $(1.07-1.91)$ & 0.02 \\
\hline Frailty & 1.07 & $(0.76-1.50)$ & 0.69 \\
\hline \multicolumn{4}{|l|}{ Cardiac comorbidities and interventions } \\
\hline Atrial fibrillation & 1.34 & $(1.08-1.66)$ & 0.01 \\
\hline Prior heart failure & 1.08 & $(0.81-1.43)$ & 0.60 \\
\hline Prior myocardial infarction & 0.98 & $(0.78-1.22)$ & 0.84 \\
\hline $\mathrm{PCl}$ & 1.18 & $(0.92-1.52)$ & 0.20 \\
\hline CABG & 0.90 & $(0.70-1.15)$ & 0.41 \\
\hline \multicolumn{4}{|l|}{ Medical comorbidities } \\
\hline Diabetes & 1.05 & $(0.86-1.29)$ & 0.65 \\
\hline Cerebrovascular disease & 0.82 & $(0.56-1.18)$ & 0.28 \\
\hline Peripheral vascular disease & 1.18 & $(1.02-1.37)$ & 0.02 \\
\hline Dementia & 1.22 & $(0.69-2.15)$ & 0.50 \\
\hline Dialysis & 1.67 & $(1.06-2.65)$ & 0.03 \\
\hline Lung disease & 1.23 & $(0.91-1.66)$ & 0.18 \\
\hline Liver disease & 2.00 & $(0.63-6.37)$ & 0.24 \\
\hline Peptic ulcer disease & 1.52 & $(1.09-2.12)$ & 0.01 \\
\hline History of bleeding & 1.10 & $(0.81-1.51)$ & 0.54 \\
\hline \multicolumn{4}{|l|}{ Laboratory markers } \\
\hline eGFR & 1.00 & $(0.99-1.0)$ & 0.36 \\
\hline Hemoglobin & 0.99 & $(0.99-1.0)$ & $<0.001$ \\
\hline \multicolumn{4}{|l|}{ Echocardiographic findings } \\
\hline Left ventricular dysfunction & 0.73 & $(0.54-0.98)$ & 0.04 \\
\hline \multicolumn{4}{|l|}{ Procedural characteristics } \\
\hline Urgent procedure & 0.98 & $(0.58-1.65)$ & 0.94 \\
\hline Valve in valve & 0.65 & $(0.48-0.87)$ & 0.004 \\
\hline Self-expandable prosthesis & 0.98 & $(0.84-1.14)$ & 0.76 \\
\hline Non-femoral vascular access site & 1.40 & $(1.08-1.81)$ & 0.01 \\
\hline TAVR year & 0.97 & $(0.92-1.03)$ & 0.31 \\
\hline \multicolumn{4}{|l|}{ Procedural complications } \\
\hline Stroke & 1.09 & $(0.82-1.45)$ & 0.56 \\
\hline Permanent pacemaker & 1.21 & $(0.83-1.77)$ & 0.31 \\
\hline Delirium & 1.24 & $(0.83-1.85)$ & 0.29 \\
\hline Bleeding, vascular complication or transfusion & 1.33 & $(1.18-1.50)$ & $<0.001$ \\
\hline
\end{tabular}

Echocardiographic findings post-TAVR

Mitral regurgitation 
Table 3 Predictors of hospital readmission within 1 year of TAVR discharge (Continued)

\begin{tabular}{|c|c|c|c|}
\hline & $\mathrm{HR}$ & $95 \% \mathrm{Cl}$ & $p$ value \\
\hline Nil/trace & reference & & \\
\hline Mild & 1.23 & $(1.10-1.38)$ & $<0.001$ \\
\hline Moderate/Severe & 1.26 & $(1.03-1.54)$ & 0.03 \\
\hline \multicolumn{4}{|l|}{ Aortic regurgitation } \\
\hline Nil/trace & reference & & \\
\hline Mild & 1.21 & $(0.97-1.52)$ & 0.10 \\
\hline Moderate/Severe & 1.13 & $(0.75-1.70)$ & 0.57 \\
\hline \multicolumn{4}{|l|}{ Previous health resource utilization } \\
\hline Hospitalization 30 days before TAVR & 1.05 & $(0.92-1.20)$ & 0.48 \\
\hline \multicolumn{4}{|l|}{ Transitional care factors } \\
\hline Rehabilitation & 1.34 & $(1.11-1.62)$ & 0.002 \\
\hline Home care & 1.18 & $(0.96-1.44)$ & 0.12 \\
\hline Family physician follow-up & 1.04 & $(0.85-1.28)$ & 0.71 \\
\hline Cardiologist follow-up & 1.41 & $(1.14-1.75)$ & 0.002 \\
\hline
\end{tabular}

Abbreviations: NYHA New York Heart Association, $P C I$ percutaneous coronary intervention, CABG coronary-aorto bypass grafting

\section{Sensitivity analyses}

After exclusion of patients who died or were readmitted in the first 30 days, there were 774 patients available for the landmark analysis (Appendix 1). The influence of transitional care factors on readmission remained the same for in-patient rehabilitation, home care, and family physician follow-up. However, the influence of cardiologist visits changed significantly, as there was no longer an increased hazard for readmission (HR 1.13, 95\% CI 0.89-1.42) associated with follow-up in the 30 days following discharge from the index hospitalization.

There were 677 patients who underwent TAVR after 2010. The overall results of this model are consistent with the primary model, suggesting that change in procedural care over time did not significantly influence hospital readmission (Appendix 2).

\section{Discussion}

We demonstrated that nearly half of patients who underwent TAVR were readmitted to hospital within 1 year, while the most common causes of readmission were heart failure and bleeding. Moreover, transitional care factors including home care, rehabilitation and physician follow-up were not associated with a reduced rate of readmission and some were associated with potentially higher hazard of readmission. While these factors cannot be endorsed for targeted improvement efforts based on our data, other modifiable targets that may potentially reduce readmission include use of bleeding avoidance strategies and optimal heart failure care.

Physician follow-up has been associated with a reduced risk of readmission after hospitalization in a variety of settings, including heart failure [4-7]. We were not able to replicate these results in the TAVR population despite high rates of pre-existing heart failure and readmission. There are several potential reasons for these divergent findings. First, our findings could be influenced by 'bias by indication'. Patients who receive earlier follow-up, and in general, more attention from healthcare providers, are likely to have more comorbid conditions, more complications, poor social supports and poor functional abilities. Although we designed a robust statistical model with the inclusion of wide-ranging patient and procedural characteristics, it is possible that this finding is a reflection of residual confounders. Secondly, our study design utilized an analytical approach centered around the use of time-varying covariates for transitional care factors. While this allowed us to avoid misclassification bias, it may have led to a 'bias' towards early and unplanned visits (as opposed to routine follow-up) which may have led to readmission. The fact that the landmark analysis did not show an association between follow-up and readmission supports these conclusions. Finally, certain conditions may be more sensitive to post-discharge care than others. Optimal heart failure management involves close follow-up for titration of medications, patient education, and monitoring weights, which adds face validity to follow-up as a tool for reducing readmissions. In contrast, close follow-up in complex medical patients with multiple comorbidities has not been associated with reduced readmission, even when combined with intense out-patient support structures and educational initiatives $[19,20]$. This suggests that while certain discrete conditions may be sensitive to close follow-up care, the heterogeneity of the TAVR population may have obscured any potential benefit.

The leading cause of hospital readmission after TAVR was heart failure and optimization of heart failure 
management may be an important component of quality improvement strategies. Multi-disciplinary heart function clinics which assist in transition of care have been deemed an essential element of heart failure care [21]. Identification of patients who are at highest risk, followed by targeted implementation of such a model, may lead to improved outcomes. Some of our study findings may support this assertion, in that we found left ventricular dysfunction to be associated with a lower risk of readmission. We hypothesize that this may be related to more careful attention to heart failure management in these patients. Future research should seek to identify which patients are at highest risk for heart failure readmission and whether these factors are modifiable, ideally through a randomized trial.

Bleeding has emerged as a major cause of readmission after TAVR [2]. It has also been shown to increase mortality well beyond the peri-procedural period and is most often gastrointestinal in origin [22]. We found several independent predictors of readmission that are all associated with bleeding, including: atrial fibrillation, peptic ulcer disease, baseline hemoglobin and bleeding complications during the index hospitalization. These findings suggest that assessment of bleeding risk and application of bleeding avoidance strategies have the potential to alter readmission rates. Several strategies could be explored in this regard including formal bleeding risk assessment (such as HAS-BLED), prescription of proton-pump inhibitors and routine optimization and work-up of pre-procedural anemia [23, 24]. Finally, these findings suggest that a risk-benefit approach should be used when prescribing anti-platelet and anti-coagulant medication to patients after TAVR, acknowledging that there is currently limited evidence to guide practice.

Several limitations of our work warrant acknowledgement. Frist, transitional care factors are complex, and their influence on hospital readmission can be difficult to study in an observational study. To mitigate this, we used a sophisticated analytical model to account for confounding factors. Since randomized control trials are unlikely to be performed in this area, our results should act to enhance our understanding of TAVR readmission. Second, our cohort included patients who underwent TAVR between 2007 and 2013, which may be criticized for being too far removed from contemporary practice. To address this concern, we performed a sensitivity analysis that included patients from 2011 to 2013 and demonstrated results consistent with our primary model. We also included procedure year as a predictor in our models and found it to be non-significant. Furthermore, since current readmission rates are in keeping with those observed in our study, we anticipate that the overall etiologic insights we have been able to generate are still applicable to current practice $[3,25]$.

\section{Conclusion}

Hospital readmission after TAVR has emerged as a major challenge, further exacerbated by growing demand. Heart failure and bleeding are important causes of morbidity in this population, suggesting that targeted interventions at these conditions might alter readmission rates. Finally, transitional care factors were not associated with a reduced rate of readmission after TAVR and these results do not support a focus on these as readmission-reducing transitional care interventions. Nonetheless, they should also not be used to dissuade clinicians from best practices surrounding hospital discharge. Further studies are needed to assess whether formally structured or targeted discharge interventions, are effective at altering readmission patterns in this population.

\section{Appendix 1}

Table 4 Landmark Analysis: Predictors of readmission from 31-365 days after discharge

\begin{tabular}{|c|c|c|c|}
\hline & $\mathrm{HR}$ & $95 \% \mathrm{Cl}$ & $p$ value \\
\hline \multicolumn{4}{|l|}{ Demographics } \\
\hline Age & 1.00 & $(0.99-1.01)$ & 0.67 \\
\hline Female sex & 0.92 & $(0.61-1.40)$ & 0.70 \\
\hline Dependent living & 0.93 & $(0.72-1.20)$ & 0.56 \\
\hline \multicolumn{4}{|l|}{ Clinical Characteristics } \\
\hline \multicolumn{4}{|l|}{ NYHA class } \\
\hline$|/| \mid$ & reference & & \\
\hline III & 1.15 & $(0.83-1.61)$ & 0.40 \\
\hline IV & 1.68 & $(1.06-2.66)$ & 0.03 \\
\hline Frailty & 0.87 & $(0.66-1.13)$ & 0.30 \\
\hline \multicolumn{4}{|c|}{ Cardiac comorbidities and interventions } \\
\hline Atrial fibrillation & 1.30 & $(1.02-1.65)$ & 0.03 \\
\hline Prior heart failure & 1.02 & $(0.83-1.26)$ & 0.84 \\
\hline $\begin{array}{l}\text { Prior myocardial } \\
\text { infarction }\end{array}$ & 0.97 & $(0.68-1.39)$ & 0.87 \\
\hline $\mathrm{PCl}$ & 1.02 & $(0.73-1.43)$ & 0.92 \\
\hline CABG & 0.96 & $(0.76-1.22)$ & 0.73 \\
\hline \multicolumn{4}{|l|}{ Medical comorbidities } \\
\hline Diabetes & 0.96 & $(0.63-1.48)$ & 0.86 \\
\hline Cerebrovascular disease & 0.70 & $(0.50-0.98)$ & 0.04 \\
\hline Peripheral vascular disease & 1.27 & $(1.02-1.57)$ & 0.03 \\
\hline Dementia & 1.03 & $(0.60-1.78)$ & 0.90 \\
\hline Dialysis & 2.01 & $(0.90-4.48)$ & 0.09 \\
\hline Lung disease & 1.33 & $(1.08-1.65)$ & 0.01 \\
\hline Liver disease & 1.52 & $(0.43-5.36)$ & 0.51 \\
\hline
\end{tabular}


Table 4 Landmark Analysis: Predictors of readmission from 31-365 days after discharge (Continued)

\begin{tabular}{|c|c|c|c|}
\hline & $\mathrm{HR}$ & $95 \% \mathrm{Cl}$ & $p$ value \\
\hline Peptic ulcer disease & 1.86 & $(1.29-2.67)$ & $<0.001$ \\
\hline History of bleeding & 1.08 & $(0.79-1.47)$ & 0.63 \\
\hline \multicolumn{4}{|l|}{ Laboratory markers } \\
\hline eGFR & 0.99 & $(0.99-1.00)$ & 0.14 \\
\hline Hemoglobin & 0.99 & $(0.99-1.00)$ & $<0.001$ \\
\hline \multicolumn{4}{|l|}{ Echocardiographic findings } \\
\hline Left ventricular dysfunction & 0.76 & $(0.57-1.02)$ & 0.07 \\
\hline \multicolumn{4}{|l|}{ Procedural characteristics } \\
\hline Urgent procedure & 1.10 & $(0.66-1.81)$ & 0.72 \\
\hline Valve in valve & 0.49 & $(0.29-0.83)$ & 0.01 \\
\hline Self-expandable prosthesis & 1.15 & $(0.89-1.48)$ & 0.29 \\
\hline $\begin{array}{l}\text { Non-femoral vascular } \\
\text { access site }\end{array}$ & 1.17 & $(0.78-1.75)$ & 0.44 \\
\hline TAVR year & 0.99 & $(0.90-1.10)$ & 0.90 \\
\hline \multicolumn{4}{|l|}{ Procedural complications } \\
\hline Stroke & 1.78 & $(1.22-2.60)$ & 0.003 \\
\hline Permanent pacemaker & 0.97 & $(0.53-1.76)$ & 0.91 \\
\hline Delirium & 1.40 & $(0.95-2.06)$ & 0.09 \\
\hline $\begin{array}{l}\text { Bleeding, vascular complication } \\
\text { or transfusion }\end{array}$ & 1.29 & $(1.22-1.37)$ & $<0.001$ \\
\hline \multicolumn{4}{|l|}{ Echocardiographic findings post-TAVR } \\
\hline \multicolumn{4}{|l|}{ Mitral regurgitation } \\
\hline $\mathrm{Nil} /$ trace & reference & & \\
\hline Mild & 1.06 & $(0.95-1.20)$ & 0.30 \\
\hline Moderate/Severe & 1.27 & $(0.97-1.66)$ & 0.08 \\
\hline \multicolumn{4}{|l|}{ Aortic regurgitation } \\
\hline $\mathrm{Nil} /$ trace & reference & & \\
\hline Mild & 1.25 & $(0.95-1.64)$ & 0.11 \\
\hline Moderate/Severe & 1.29 & $(0.77-2.15)$ & 0.34 \\
\hline \multicolumn{4}{|l|}{ Previous health resource utilization } \\
\hline $\begin{array}{l}\text { Hospitalization } 30 \text { days } \\
\text { before TAVR }\end{array}$ & 1.21 & $(0.91-1.61)$ & 0.20 \\
\hline \multicolumn{4}{|c|}{ Transitional care factors in first 30 days } \\
\hline Rehabilitation & 1.55 & $(1.37-1.75)$ & $<0.001$ \\
\hline Home care & 0.94 & $(0.78-1.13)$ & 0.51 \\
\hline $\begin{array}{l}\text { Family physician } \\
\text { follow-up }\end{array}$ & 0.73 & $(0.51-1.05)$ & 0.09 \\
\hline Cardiologist follow-up & 1.13 & $(0.89-1.42)$ & 0.32 \\
\hline
\end{tabular}

Abbreviations: NYHA New York Heart Association, $P C l$ percutaneous coronary intervention, $C A B G$ coronary-aorto bypass grafting

\section{Appendix 2}

Table 5 Contemporary Cohort (after 2010): Predictors of hospital readmission within 365 days of discharge

\begin{tabular}{llll}
\hline & $H R$ & $95 \% \mathrm{Cl}$ & $p$ value \\
\hline Demographics & & & \\
$\quad$ Age & 1.00 & $(1.00-1.01)$ & 0.49 \\
Female sex & 0.80 & $(0.51-1.24)$ & 0.32 \\
Dependent living & 0.90 & $(0.64-1.26)$ & 0.53
\end{tabular}

Clinical Characteristics

NYHA class

$\begin{array}{clll}\text { I/I } & \text { reference } & & \\ \text { III } & 1.03 & (0.78-1.34) & 0.85 \\ \text { IV } & 1.36 & (0.99-1.87) & 0.06 \\ \text { Frailty } & 0.92 & (0.64-1.33) & 0.67\end{array}$

Cardiac comorbidities and interventions

Atrial fibrillation $\quad 1.29$

Prior heart failure

$(1.02-1.63) \quad 0.04$

$(0.74-1.69) \quad 0.59$

Prior myocardial infarction $\quad 1.03$

$\mathrm{PCl}$

$(0.73-1.44) \quad 0.88$

CABG

$(0.84-1.64) \quad 0.35$

$(0.57-1.12) \quad 0.19$

Medical comorbidities

Diabetes

Cerebrovascular disease

$(0.78-1.19) \quad 0.74$

Peripheral vascular disease

$(0.48-1.17) \quad 0.21$

Dementia

$(1.12-1.70) \quad 0.003$

$(0.56-3.08) \quad 0.53$

Dialysis

Lung disease

$(1.18-2.59) \quad 0.01$

Liver disease $\quad 1.58$

$(0.66-1.98) \quad 0.62$

$(0.22-11.2) \quad 0.65$

Peptic ulcer disease

$(1.01-2.27) \quad 0.04$

History of bleeding

$(0.72-1.66) \quad 0.69$

Laboratory markers

eGFR

$(0.99-1.00) \quad 0.19$

Hemoglobin

$(0.99-1.00)<0.001$

Echocardiographic findings

Left ventricular dysfunction

0.78

$(0.59-1.04) \quad 0.09$

Procedural characteristics

Urgent procedure

$(0.64-1.84) \quad 0.77$

Valve in valve

$(0.59-0.99) \quad 0.04$

Self-expandable prosthesis

$(0.82-1.07) \quad 0.36$

Non-femoral vascular

$(1.05-1.81) \quad 0.02$

access site

TAVR year

$(0.82-1.04) \quad 0.18$

Procedural complications

Stroke

Permanent pacemaker

$(0.80-2.02) \quad 0.32$

Delirium

$(0.92-2.22) \quad 0.11$

$(0.87-1.85) \quad 0.23$

Bleeding, vascular complication 
Table 5 Contemporary Cohort (after 2010): Predictors of hospital readmission within 365 days of discharge (Continued)

\begin{tabular}{|c|c|c|c|}
\hline & $\mathrm{HR}$ & $95 \% \mathrm{Cl}$ & $p$ value \\
\hline \multicolumn{4}{|l|}{ or transfusion } \\
\hline \multicolumn{4}{|c|}{ Echocardiographic findings post-TAVR } \\
\hline \multicolumn{4}{|l|}{ Mitral regurgitation } \\
\hline $\mathrm{Nil} /$ trace & reference & & \\
\hline Mild & 1.23 & $(0.86-1.76)$ & 0.26 \\
\hline Moderate/Severe & 1.29 & $(0.89-1.86)$ & 0.17 \\
\hline \multicolumn{4}{|l|}{ Aortic regurgitation } \\
\hline Nil/trace & reference & & \\
\hline Mild & 1.24 & $(1.05-1.47)$ & 0.01 \\
\hline Moderate/Severe & 1.35 & $(0.95-1.93)$ & 0.10 \\
\hline \multicolumn{4}{|c|}{ Previous health resource utilization } \\
\hline $\begin{array}{l}\text { Hospitalization } 30 \text { days } \\
\text { before TAVR }\end{array}$ & 1.09 & $(0.88-1.35)$ & 0.44 \\
\hline \multicolumn{4}{|l|}{ Transitional care factors } \\
\hline Rehabilitation & 1.34 & $(1.12-1.61)$ & 0.002 \\
\hline Home care & 1.12 & $(0.85-1.48)$ & 0.42 \\
\hline Family physician follow-up & 0.93 & $(0.69-1.25)$ & 0.63 \\
\hline Cardiologist follow-up & 1.29 & $(1.05-1.58)$ & 0.02 \\
\hline
\end{tabular}

Abbreviations: NYHA New York Heart Association, $P C l$ percutaneous coronary intervention, $C A B G$ coronary-aorto bypass grafting

\section{Abbreviations}

AS: Aortic stenosis; NYHA: New York Heart Association; PCI: Percutaneous coronary intervention; TAVR: Trans-catheter aortic valve replacement

\begin{abstract}
Acknowledgments
The authors acknowledge that clinical registry data used in this publication is from participating hospitals through CorHealth Ontario which serves as an advisory body to the Ontario Ministry of Health and Long-Term Care (MOHLTC), is funded by the MOHLTC, and is dedicated to improving the quality, efficiency, access, and equity in the delivery of the continuum of adult cardiac services in Ontario, Canada. This study was supported by the Institute for Clinical Evaluative Sciences (ICES), which is funded by an annual grant from the MOHLTC. The opinions, results, and conclusions reported in this article are those of the authors and are independent from the funding sources. No endorsement by ICES or the MOHLTC is intended or should be inferred. Parts of this material are based on data and/or information compiled and provided by $\mathrm{CIHI}$. However, the analyses, conclusions, opinions, and statements expressed in the material are those of the authors and not necessarily those of $\mathrm{CIHI}$.
\end{abstract}

\section{Funding}

The study is supported a Foundation grant (FDN-154333) and an operating grant (148865) from the Canadian Institutes of Health Research. The funding body had no role in the design of the study, collection, analysis and interpretation of data and writing of the manuscript. Dr. Ko is supported by a Mid-Career Investigator award from the Heart and Stroke Foundation of Canada (HSFC), Ontario Provincial Office. Dr. Wijeysundera is supported by a Distinguished Clinician Scientist Award from the Heart and Stroke Foundation of Canada. Dr. Austin is supported by a Career Investigator Award from the Heart and Stroke Foundation. Dr. Tu is supported by a Tier 1 Canada Research Chair in Health Services Research.

\section{Availability of data and materials}

The data that support the findings of this study are available from the Institute for Clinical Evaluative Sciences but restrictions apply to the availability of these data, which were used under license for the current study, and so are not publicly available. Data are however available from the authors upon reasonable request and with permission of Institute for Clinical Evaluative Sciences.

\section{Authors' contributions}

Each author has contributed significantly to our manuscript, including the conception and design (AC, DK, JT, HW, PA), or analysis and interpretation of data (AC, DK, JT, HW, PA, SF), or drafting of the manuscript or revising it critically for important intellectual content (AC, DK, JT, HW, PA, SF). All authors have given final approval of the manuscript submitted

\section{Ethics approval and consent to participate}

This study was approved by the institutional review board at Sunnybrook Health Sciences Centre, Toronto, Canada. Local hospital ethics board approval was obtained at each of the 10 hospitals performing TAVR in Ontario at the time of the study. Based on Ontario's Privacy Legislation, the need for individual patient consent was waived.

\section{Consent for publication}

Not applicable.

\section{Competing interests}

Dr. Wijeysundera received research funding from Medtronic Inc. and Edwards Lifesciences. The remaining authors declare that they have no competing interests.

\section{Publisher's Note}

Springer Nature remains neutral with regard to jurisdictional claims in published maps and institutional affiliations.

\section{Author details}

${ }^{1}$ Schulich Heart Centre, Division of Cardiology, Sunnybrook Health Sciences Centre, 2075 Bayview Ave, Toronto, Ontario M4N 3M5, Canada. ${ }^{2}$ Department of Medicine, University of Toronto, Suite RFE 3-805, 200 Elizabeth Street, Toronto, Ontario M5G 2C4, Canada. ${ }^{3}$ Institute of Health Policy, Management and Evaluation, University of Toronto, 155 College Street, Suite 425, Toronto, Ontario M5T 3M6, Canada. ${ }^{4}$ Institute for Clinical Evaluative Sciences, G-106 2075 Bayview Ave, Toronto, Ontario M4N 3M5, Canada.

Received: 15 June 2018 Accepted: 14 January 2019

Published online: 18 January 2019

\section{References}

1. Czarnecki A, Qiu F, Koh M, Alter DA, Austin PC, Fremes SE, et al. Trends in the incidence and outcomes of patients with aortic stenosis hospitalization. Am Heart J. 2018;199:144-9.

2. Nombela-Franco L, del Trigo M, Morrison-Polo G, Veiga G, Jimenez-Quevedo $\mathrm{P}$, Abdul-Jawad Altisent $\mathrm{O}$, et al. Incidence, causes, and predictors of early $(</=30$ days $)$ and late unplanned hospital readmissions after Transcatheter aortic valve replacement. JACC Cardiovasc Interv. 2015;8(13):1748-57.

3. Holmes DR Jr, Brennan JM, Rumsfeld JS, Dai D, O'Brien SM, Vemulapalli S, et al. Clinical outcomes at 1 year following transcatheter aortic valve replacement. JAMA. 2015;313(10):1019-28.

4. Czarnecki A, Chong A, Lee DS, Schull MJ, Tu JV, Lau C, et al. Association between physician follow-up and outcomes of care after chest pain assessment in high-risk patients. Circulation. 2013;127(13):1386-94.

5. Sharma G, Kuo YF, Freeman JL, Zhang DD, Goodwin JS. Outpatient followup visit and 30-day emergency department visit and readmission in patients hospitalized for chronic obstructive pulmonary disease. Arch Intern Med. 2010;170(18):1664-70.

6. Coleman EA, Parry C, Chalmers S, Min SJ. The care transitions intervention: results of a randomized controlled trial. Arch Intern Med. 2006;166(17):1822-8.

7. Lee DS, Stukel TA, Austin PC, Alter DA, Schull MJ, You JJ, et al. Improved outcomes with early collaborative care of ambulatory heart failure patients discharged from the emergency department. Circulation. 2010;122(18): 1806-14.

8. Hernandez AF, Greiner MA, Fonarow GC, Hammill BG, Heidenreich PA Yancy CW, et al. Relationship between early physician follow-up and 30-day readmission among Medicare beneficiaries hospitalized for heart failure. JAMA. 2010;303(17):1716-22. 
9. Czarnecki A, Qiu F, Koh M, Prasad TJ, Cantor WJ, Cheema AN, et al. Clinical outcomes after trans-catheter aortic valve replacement in men and women in Ontario, Canada. Catheter Cardiovasc Interv. 2017;90(3):486-94.

10. Wijeysundera HC, Qiu F, Koh M, Prasad TJ, Cantor WJ, Cheema A, et al. Comparison of outcomes of balloon-expandable versus self-expandable Transcatheter heart valves for severe aortic stenosis. Am J Cardiol. 2017; 119(7):1094-9.

11. Tu K, Campbell NR, Chen ZL, Cauch-Dudek KJ, McAlister FA. Accuracy of administrative databases in identifying patients with hypertension. Open Med. 2007; (1):e18-26.

12. Hux JE, Ivis F, Flintoft V, Bica A. Diabetes in Ontario: determination of prevalence and incidence using a validated administrative data algorithm. Diabetes Care. 2002;25(3):512-6.

13. Schultz SE, Rothwell DM, Chen Z, Tu K. Identifying cases of congestive heart failure from administrative data: a validation study using primary care patient records. Chronic Dis Inj Can. 2013;33(3):160-6.

14. Mclsaac DI, Bryson GL, van Walraven C. Association of Frailty and 1-year postoperative mortality following major elective noncardiac surgery: a population-based cohort study. JAMA Surg. 2016;151(6):538-45.

15. Lau B, Cole SR, Gange SJ. Competing risk regression models for epidemiologic data. Am J Epidemiol. 2009;170(2):244-56.

16. van Walraven C, Dhalla IA, Bell C, Etchells E, Stiell IG, Zarnke K, et al. Derivation and validation of an index to predict early death or unplanned readmission after discharge from hospital to the community. CMAJ. 2010; 182(6):551-7.

17. Eastwood CA, Howlett JG, King-Shier KM, McAlister FA, Ezekowitz JA, Quan $\mathrm{H}$. Determinants of early readmission after hospitalization for heart failure. Can J Cardiol. 2014;30(6):612-8.

18. Krumholz HM, Lin Z, Drye EE, Desai MM, Han LF, Rapp MT, et al. An administrative claims measure suitable for profiling hospital performance based on 30-day all-cause readmission rates among patients with acute myocardial infarction. Circ Cardiovasc Qual Outcomes. 2011;4(2):243-52.

19. Dhalla IA, O'Brien T, Morra D, Thorpe KE, Wong BM, Mehta R, et al. Effect of a postdischarge virtual ward on readmission or death for high-risk patients: a randomized clinical trial. JAMA. 2014;312(13):1305-12.

20. Grafft CA, McDonald FS, Ruud KL, Liesinger JT, Johnson MG, Naessens JM. Effect of hospital follow-up appointment on clinical event outcomes and mortality. Arch Intern Med. 2010;170(11):955-60.

21. Writing Committee M, Yancy CW, Jessup M, Bozkurt B, Butler J, Casey DE Jr, et al. ACCF/AHA guideline for the management of heart failure: a report of the American College of Cardiology Foundation/American Heart Association task force on practice guidelines. Circulation. 2013;128(16):e240-327.

22. Genereux P, Cohen DJ, Mack M, Rodes-Cabau J, Yadav M, Xu K, et al. Incidence, predictors, and prognostic impact of late bleeding complications after transcatheter aortic valve replacement. J Am Coll Cardiol. 2014;64(24): 2605-15.

23. Ray WA, Chung CP, Murray KT, Smalley WE, Daugherty JR, Dupont WD, et al. Association of Proton Pump Inhibitors with Reduced Risk of warfarinrelated serious upper gastrointestinal bleeding. Gastroenterology. 2016; 151(6):1105-12 e10.

24. Schjerning Olsen AM, Lindhardsen J, Gislason GH, McGettigan P, Hlatky MA, Fosbol $\mathrm{E}$, et al. Impact of proton pump inhibitor treatment on gastrointestinal bleeding associated with non-steroidal anti-inflammatory drug use among post-myocardial infarction patients taking antithrombotics: nationwide study. BMJ. 2015;351:h5096.

25. Wijeysundera HC KD, Tu JV, Welsh R. Canadian Cardiovascular Society National Quality Report: Transcatheter Aortic Valve Implantation. 2016.

Ready to submit your research? Choose BMC and benefit from:

- fast, convenient online submission

- thorough peer review by experienced researchers in your field

- rapid publication on acceptance

- support for research data, including large and complex data types

- gold Open Access which fosters wider collaboration and increased citations

- maximum visibility for your research: over $100 \mathrm{M}$ website views per year

At BMC, research is always in progress.

Learn more biomedcentral.com/submissions 